\title{
Effects of knowledge of results on schematic concept formation
}

\author{
JOIN G. PEARRE and ELVIS C. JONES, Augusta College. \\ Augusta, Ga.
}

An earlier experiment found that knowledge of results $(K R)$ interfered with schematic concept formation (SCF) when highly redundant visual patterns were employed. The present experiment was a partial replication of the earlier experiment. In contrast to the earlier findings, the present experiment produced evidence that $K R$ facilitated SCF. Furthermore, SCF did not occur when KR was not provided. It was concluded that $K R$ may be indispensable in $S C F$ if the nature of the task allows $S s$ to readily adopt and maintain an erroneous set. $K R$ should help Ss discover that the schema is the stimulus feature to which they should respond.

Schema theory (Attneave, 1957; Oldfield, 1954) has led to the conclusion that under certain conditions humans are capable of assigning objects to appropriate categories purely on the basis of experience with the objects themselves. This process has been called schematic concept formation (SCF) and is distinguished from more traditional concept formation by the fact that the process can occur without knowledge of results (KR), and without experience with the concept prototype (Evans, 1967a). Furthermore, SCF may occur without awareness (Edmonds, Mueller, \& Evans, 1966).

Although SCF undoubtably can occur without $K R$, it nevertheless seems likely that KR may be indispensable if the SCF task is sufficiently difficult. For example, SCF will be extremely difficult without $K R$ when the members of a class have little in common. Also, KR may be a critical factor whenever the schema that is to be abstracted is very similar to other schemata with which objects could be mistakenly grouped.

The notion that KR aids SCF has been supported by empirical research. For example, KR has been found to accelerate SCF in an oddity task employing visual patterns (Edmonds, Mueller, \& Evans, 1966). However, Brown, Walker, \& Evans (1968) have recently reported that $\mathrm{KR}$ actually interfered with SCF in an identification task employing $70 \%$ redundant visual patterns. In an earlier account of the same experiment, Walker, Brown, \& Evans (1967, Experiment 1), reported no significant effect of KR when the patterns were $40 \%$ redundant. This finding is not unusual, since under the best conditions Ss have considerable difficulty in learning $40 \%$ redundant patterns. As a result, the use of KR during the limited number of training trials (20) could not be expected to significantly enhance SCF. However, the results with $70 \%$ redundant patterns are unusual and contradict the findings of most studies dealing with concept formation and KR. If Brown et al's findings are reliable and true of SCF in general, the implications are far-reaching. Since a wide variety of our concepts are schematic, it would mean that a very basic method employed throughout the educational community is not only ineffective, but actually detrimental to learning.

The present experiment attempted to replicate the portion of Brown et al's experiment which employed $70 \%$ redundant patterns. It was hypothesized that KR should facilitate rather than inhibit performance.

\section{METHOD}

Histoform patterns were produced by using the rules employed by the VARGUS 7 computer program (Evans, 1967c) except that the patterns consisted of columns of reclining capital Os produced by an IBM model 11 electric typewriter, and duplicated on a mimeograph machine. The most probable sequence (MPS) of schema Family 1 was: $1,4,5,2,7,6,3$. The MPS of the schema Family 2 was: 1, 3, 7, 4, 2, 5, 6, and for schema Family 3: 1, 7, 3, $6,2,5,4$. The patterns were $70 \%$ redundant (Attneave, 1959; Evans, 1967b).

The Ss were 20 experimentally naive undergraduate students randomly assigned to two groups of 10 Ss. No pretraining was given in order to avoid confusing the Ss when either the task or the stimuli were changed. Each $S$ was given 20 trials, where each trial proceeded as follows: For $20 \mathrm{sec} S$ looked at a single pattern randomly drawn from schema Family 1 . He was then instructed to turn the page and was given $20 \mathrm{sec}$ to examine three numbered patterns, one randomly drawn from each of the three schema families. The position of patterns from each schema family was randomly assigned.

The $\mathrm{S}$ was instructed to select, from among the three patterns, the one most similar to the single pattern he had just seen. He was then told to turn the page and was given $10 \mathrm{sec}$ to look at the following page; for the no knowledge of results (NKR) Ss the page was blank, for the KR Ss the number of the correct pattern was printed on the page. The meaning of the number was explained before the experiment began. A blackened sheet was inserted between each page to prevent $S$ from seeing the preceding or following pages.

\section{RESULTS AND DISCUSSION}

The mean number of patterns correctly identified by the KR group was 9.4, and the NKR group 7.0. This difference was statistically significant $(t=1.83$, df $=18, p<.05)$ and in the predicted direction.

The brevity of Brown et al's methods section makes it impossible to account for the discrepancy between the present findings and their results. For example, as the MPSs employed by Brown et al, were not stated, it can not be determined if the schemata in the present study differed in the ease with which they could be distinguished. Likewise, the manner in which $\mathrm{KR}$ was administered in the present study may have differed from the method used by Brown et al. It is not clear whether they provided $K R$ by allowing the $S$ to view the correct pattern, or the number of the correct pattern, on the KR page. Of critical importance is the fact that they do not state whether patterns from the same schema family were used as the standard throughout the experiment.

Brown et al report that their Ss received 20 pretraining trials during which Ss viewed circles, triangles, and squares. Although they state that this procedure was "irrelevant" to their study, it may very well be that the procedure accounts for the discrepancy between their findings and those of the present study. However, without further information, this is impossible to judge.

In any case, there are several reasons why $\mathrm{KR}$ should facilitate SCF in the present task. Before a $S$ learns to attend to the schema, VARGUS 7 patterns drawn from different schema families often appear extremely similar on the basis of a number of extraneous variables, including the apparent area, the absolute heights of specific columns (e.g., the first and last columns), the overall slant of the patterns, etc. In fact, since the NKR Ss in the present study did not perform significantly above chance $(z=.035, \mathrm{p}=.48)$, it seems likely that they were judging the similarity of patterns on the basis of features other than the schema. Furthermore, in a study involving free-sorting of patterns from different schema families, Evans \& Arnoult (1967) found that in the absence of KR, only $21 \%$ of their Ss were clearly sorting on the basis of the schema. Knowledge of results should help eliminate erroneous sets (area, slant, etc.), and thereby increase the probability that Ss will attend to the relevant factor, viz, the schema.

\section{REFERENCES}

ATTNEAVE, F. Applications of information theory to psychology. New York: Holt, Rinehart, \& Winston, 1959.

ATTNEAVE, F. Transfer of experience with a class-schema to identificationlearning of patterns and shapes. Journal of Experimental Psychology, $1957,54,81.88$.

BROWN, B. R., WALKER, D., \& EVANS, S. H. Schematic concept formation as a function of constraint redundancy and knowledge of results. Psychonomic Science, 1968, 11, 75-76.

EDMONDS, E. M., MUELLER, M. R., \& EVANS, S. H. Effects of knowledge 
of results on mixed schematic discrimination. Psychonomic Science. 1960. 6.377 .378 .

EVANS. S. H. A brief statement of schema theory. Psychonomic Science, $1967 \mathrm{a}, 8.87 .88$.

EVANS. S. H. Redundancy as a variable in pattern perception. Psychological Bulletin. 1967b, 67, 10+113.

EVANS, S. H. VARGUS 7: Computed patterns from Markov processes. Behavioral Science, 1967:, 12, 323.328.

EVANS, S. H., \& ARNOULT, M. D. Schematic concept formation: Demonstration in a free sorting task. Psychonomic Science, 1967, 9.
221-222.

OLDFIELD, R. C. Memory mechanisms and the theory of schemata. British Journal of Psychology, 1954, 45, 14-23.

WALKER. D.. BROWN, B. R., \& EVANS. S. H. Schema discrimination as a function of redundancy and knowledge of results. Paper presented at the Southwestern Psychological Association Convention, Houston, Texas, April, 1967.

\section{NOTE}

1. This was an undergraduate research project conducted by the first author and sponsored by the second author. 